\title{
In Situ Fibre Composites from Poly(phenylene sulphide)/Thermotropic Liquid Crystalline Polymer Blends. Melting, Crystallization, and Phase Behavior
}

\author{
T. G. Gopakumar, S. Ponrathnam, C. R. Rajan, ${ }^{\dagger}$ and Alain Fradet* \\ Polymer Science and Engineering Group, Chemical Engineering Division, National Chemical Laboratory, \\ Pune, India-411008 \\ * Laboratoire de Synthese Macromoleculaire, Universite Pierre et Marie Curie, F-75252 Paris Cedex 05, France
}

(Received December 13, 1996)

\begin{abstract}
Melting, crystallization and phase behavior of the blends of poly(phenylene sulphide) (PPS) and an aliphatic-aromatic thermotropic liquid crystalline polymer (TLCP), were investigated using differential scanning calorimetry (DSC) and polarized light optical microscopy (PLOM). The equilibrium melting temperature $\left(T_{\mathrm{m}}^{0}\right)$ and the crystal lamellar thickness of PPS phase decreases with an increase in TLCP concentration. This phenomenon can be ascribable to the nucleating effect of TLCP on the spherulite growth of PPS phase. Phase diagram shows that the PPS/TLCP blend crystallizes in well separated temperature regimes and that the PPS component will always be solidified before the crystallization of TLCP begins. The crystallization temperature of PPS increases with the addition of TLCP. The PPS/TLCP blends exists as phase separated in the melt state. The reduction in the spherulite size of PPS phase, as revealed by PLOM, indicates that the spherulitic growth rate as well as the overall crystallization rate of PPS is influenced by the presence of TLCP.

KEY WORDS Poly(phenylene sulphide) / Thermotropic Liquid Crystalline Polymer / Polymer Blends / Melting Behavior / Crystallization Behavior / Phase Behavior /
\end{abstract}

Poly(phenylene sulphide) (PPS) and thermotropic liquid crystalline polymers (TLCP) are high strength/high temperature specialty polymers which find applications in the electrical and electronic industries. ${ }^{1}$ Blends of PPS with TLCPs are of interest for several reasons. ${ }^{2-12}$ The motivation was first to use the high-tensile modulus of the TLCPs in the solid state to reinforce the PPS matrix. Secondly, the low viscosity of the TLCPs can reduce the overall melt viscosity of the blend and thus act as a good processing aid. The thermotropic liquid crystalline polymer, which is initially dispersed as spheres or droplets, can be elongated to form fibrils in adequate flow fields to give an in situ reinforcement. Elongated fine fibrils can effectively reinforce the matrix polymer. Moreover, the TLCP phase has been shown to influence the crystallizability of the PPS matrix. ${ }^{7-10}$

Several studies ${ }^{3-7}$ have been published on the blends of PPS with wholly aromatic commercially available TLCPs such as Vectra-A950 (copolyester of $25 \mathrm{~mol} \%$ of 2-hydroxy-6-naphthoic acid (HNA) and $75 \mathrm{~mol} \%$ 4hydroxy benzoic acid (HBA)) and Vectra-B950 (copolyester of $60 \mathrm{~mol} \%$ 2-hydroxy-6-naphthoic acid, $20 \mathrm{~mol} \%$ terephthalic acid and $20 \mathrm{~mol} \%$ 4-aminophenol). Subramanian and Isayev ${ }^{3}$ found that for effective reinforcement and betterment of mechanical properties, the melt viscosity of TLCP must be lower than that of the PPS at the processing temperature. The mechanical properties estimated for PPS/Vectra-A950 were lower than that of TLCP and no fibrillation of the TLCP phase in the matrix was found. Previous studies ${ }^{4-7}$ lead to the conclusion that maximum fibrillation occurs when the melt viscosity ratio of the original components is close to unity. The presence of fibres seems to be a necessary attribute for improving the mechanical properties. Thus, the viscosity ratio between the dispersed phase and the matrix is an important factor for the phase morphology of the blends. Heino and Seppala ${ }^{5,6}$ reported that PPS/Vectra-A950 blends were two phase systems and that the properties were dependent on miscibility, interfacial adhesion between the blend components and orientation of the TLCP phase.

The melting, crystallization, and phase behavior of the blend have very significant role in determining its processing characteristics and properties. In this communication, we present the results of our investigation on the melting, crystallization, and phase behavior of blends of PPS and TLCP by different techniques such as differential scanning calorimetry (DSC) and polarized light optical microscopy (PLOM).

\section{EXPERIMENTAL}

PPS used was a commercial grade Ryton V-1 $\left(M_{w}=\right.$ 60000) manufactured by Philips Petroleum Company. This material shows a melting transition of $282.0^{\circ} \mathrm{C}$ and $\Delta H$ of $43.2 \mathrm{~J} \mathrm{~g}^{-1}$. The aliphatic-aromatic TLCP was synthesized from poly(ethylene terephthalate) (PET) $(70 \mathrm{~mol} \%)$ and 4 -acetoxybenzoic acid $(30 \mathrm{~mol} \%) .{ }^{13}$ The intrinsic viscosity of the PET used in the synthesis was $0.6 \mathrm{dL} \mathrm{g}^{-1}$. TLCP exhibited birefringence when it was heated up to $300^{\circ} \mathrm{C}$ and then cooled down. It showed a glass transition temperature of $65^{\circ} \mathrm{C}$ and crystal to nematic transition at $197^{\circ} \mathrm{C}$.

\section{Preparation of Blends}

Powders of the liquid crystalline TLCP and PPS were dried at $130^{\circ} \mathrm{C}$ under vacuum for $8 \mathrm{~h}$ prior to mixing. The PPS/TLCP blends with a TLCP content in the range $3,5,10,20,30,50,75$, and $90 \%(\mathrm{wt} / \mathrm{wt})$ were prepared in a $30 \mathrm{~mL}$ mixer attached to a Brabender Plasticorder

† To whom correspondence should be addressed (E-mail: rajan/@ems.ncl.res.in). 
at $300^{\circ} \mathrm{C}$ and $100 \mathrm{rpm}$ for $5 \mathrm{~min}$ under nitrogen. Blank samples of both PPS and TLCP were also subjected to the same treatment.

\section{Thermal Analysis}

Thermal properties were measured by a Mettler TA4000 series DSC. The apparatus was calibrated with Indium at different scanning rates. The lag between sample and pan holder temperature was also taken into account, and computed through Indium crystallization tests as described by Eder and Wlochowicz. ${ }^{14}$ The weight of samples were kept constant $(6.00 \pm 0.10 \mathrm{mg})$ throughout the analysis so that the effect of weight change on the enthalpy change can be minimized. The heat of fusion and heat of crystallization were determined from the peak area of the DSC thermograms.

The samples were heated at a rate of $20^{\circ} \mathrm{C} \mathrm{min}^{-1}$ to $320^{\circ} \mathrm{C}$ where it was held for $10 \mathrm{~min}$ in order to ensure that it melts completely, and quenched to different isothermal crystallization temperatures, $\left(T_{\mathrm{c}}\right): 230,235$, $240,245,250$, and $255^{\circ} \mathrm{C}$. The samples were kept for one hour at each crystallization temperature ${ }^{15,16}$ and then reheated to $320^{\circ} \mathrm{C}$ at the rate of $20^{\circ} \mathrm{C} \mathrm{min}^{-1}$. The melting points corresponding to this heating cycle were noted.

\section{PLOM}

The morphology of the spherulites of pure PPS and PPS in blends was observed with a hot stage coupled Leitz microscope and under crossed polarizers. The blend samples were sandwiched between a microslide and a cover glass and were melted at $320^{\circ} \mathrm{C}$ for 1 min under slight pressure. The slides containing thin film were then transferred to the hot stage. The phase separation process of the blends in molten state were observed at various temperature and time.

\section{RESULTS AND DISCUSSION}

\section{Melting Behavior}

The equilibrium melting temperature is the most important macroscopic quantity to characterize a given crystal of a flexible linear macromolecule, especially, in blends with another polymer. ${ }^{16-19}$ Therefore, we determined the equilibrium melting point $T_{\mathrm{m}}^{0}$ of PPS as well as in PPS/TLCP blends by Hoffman-Weeks analysis. ${ }^{15}$ This analysis involves isothermal crystallization of the sample at various temperatures $\left(T_{\mathrm{c}}\right)$ and plotting the observed melting point $\left(T_{\mathrm{m}}\right)$ as a function of $T_{\mathrm{c}}$. Figure 1 shows typical DSC endotherms of PPS and PPS (70)/TLCP (30) blends obtained after isothermal crystallization at $230,235,240,245,250$, and $255^{\circ} \mathrm{C}$ for one hour. The melting transition temperatures $\left(T_{\mathrm{m}}\right)$ of PPS and PPS/TLCP blend increases with crystallization temperature $\left(T_{\mathrm{c}}\right)$.

The Hoffman-Weeks equation

$$
T_{\mathrm{m}}=\eta T_{\mathrm{c}}+(1-\eta) T_{\mathrm{m}}^{0}
$$

predicts a linear relation between $T_{\mathrm{m}}$ and $T_{\mathrm{c}}$. The equilibrium melting point $T_{\mathrm{m}}^{0}$ is obtained from the intersection of this line with the $T_{\mathrm{m}}=T_{\mathrm{c}}$ equation as shown in Figure 2. The slope of the Hoffman-Weeks plot, $\eta$, assumes values between 0 and 1 and may be regarded as a measure of the stability, i.e., the lamellar thickness,

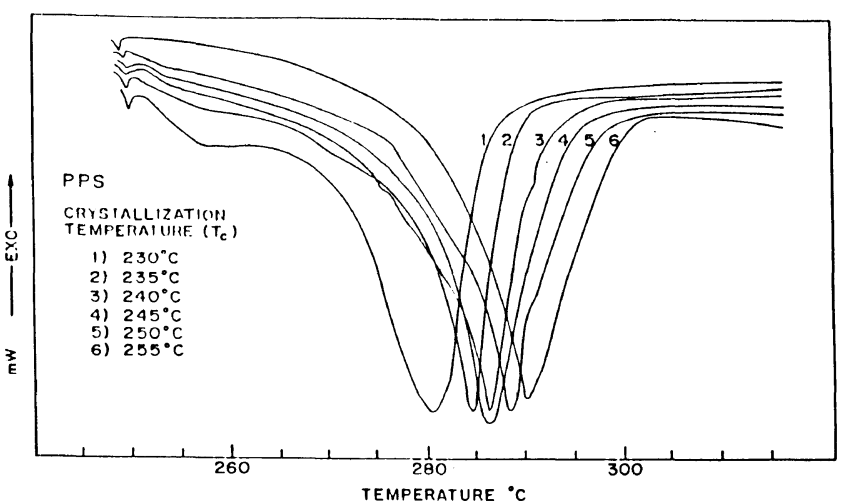

(a)

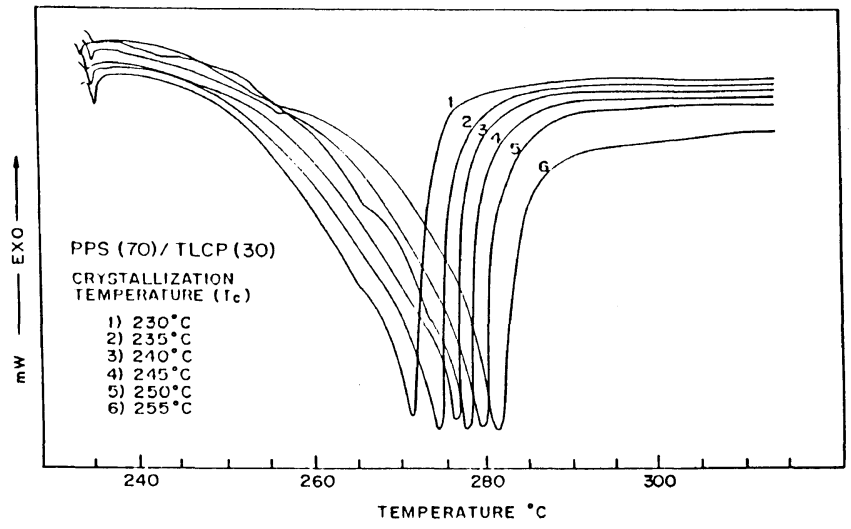

(b)

Figure 1. Typical DSC thermograms obtained after isothermal crystallization at various temperatures for one hour: (a) PPS and (b) PPS (70)/TLCP (30) blend.

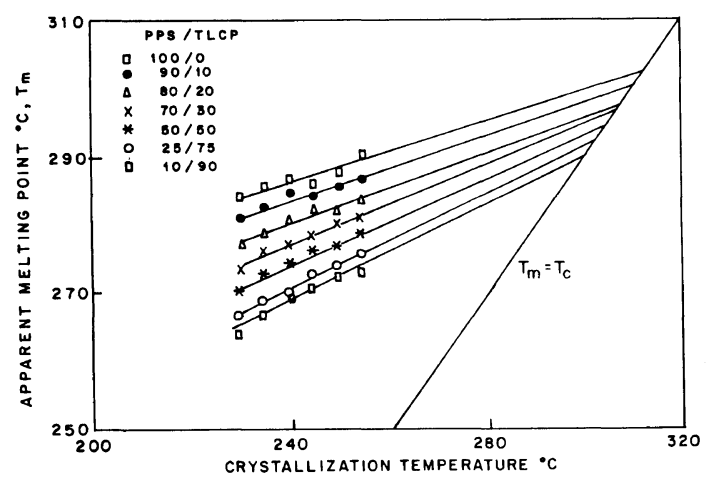

Figure 2. Hoffman-Weeks plots for pure PPS and PPS/TLCP blends.

of the crystals undergoing the melting process. ${ }^{15}$ A value of $\eta=0$ implies that the crystals are perfectly stable $\left(T_{\mathrm{m}}=T_{\mathrm{m}}^{0}\right.$ at all $\left.T_{\mathrm{c}}\right)$, whereas a value of $\eta=1$ reflects inherently unstable crystals.

Figure 2 shows the Hoffman-Weeks plots for PPS as well as in PPS/TLCP blends. The $T_{\mathrm{m}}^{0}$ and $\eta$ values are tabulated in Table I. The value $\mathrm{f}$ the equilibrium melting point of pure PPS obtained $\left(304.1^{\circ} \mathrm{C}\right)$ is in good agreement with previously reported values which are in the range of $303-315^{\circ} \mathrm{C} .{ }^{20-23}$ It is clear that the equilibrium melting point of PPS in PPS/TLCP blends decreases with increase TLCP concentration while the slope of Hoffman-Weeks plots, $\eta$, increases with TLCP content. This is indicative of a decrease in lamellar thickness of PPS on blending with TLCP.

The analysis of the melting behaviour of a crystalline 
Table I. Hoffman-Weeks analysis

\begin{tabular}{|c|c|c|}
\hline \multirow{2}{*}{$\begin{array}{l}\text { PPS/TLCP } \\
\text { blends }\end{array}$} & Equilibrium melting point & Slope \\
\hline & $T_{\mathrm{m}}^{0}$ & $\eta$ \\
\hline $100 / 0$ & 304.1 & 0.179 \\
\hline $90 / 10$ & 301.3 & 0.229 \\
\hline $80 / 20$ & 299.6 & 0.263 \\
\hline $70 / 30$ & 298.5 & 0.303 \\
\hline $50 / 50$ & 296.0 & 0.348 \\
\hline $25 / 75$ & 294.1 & 0.360 \\
\hline $10 / 90$ & 289.1 & 0.374 \\
\hline
\end{tabular}

component in semicrystalline polymer blends is an important tool in studying the phase behaviour of polymer mixtures. ${ }^{18,19}$ In miscible blends, the melting point of the crystalline component is usually lowered with respect to the pure polymer as a result of thermodynamically favorable interactions. ${ }^{24}$ However, it is difficult to interpret any specific interaction, either chemical or physical, between PPS and TLCP in the PPS/TLCP blend system. The depression in the equilibrium melting point of PPS/TLCP blends with respect to pure PPS can be ascribable to the nucleation effect of TLCP on the spherulite growth of PPS phase. In the presence of TLCP phase, the thermal nucleated process in PPS is known to lead to rod-shaped growth ${ }^{25}$ and thereby cause a reduction in the spherulite size. In molten state, TLCP chains could diffuse into the PPS phase and get entrapped within its spherulite during crystallization. This will lead to the formation of less stable crystals. This observation is in accordance with our previous study $^{25}$ in which we reported that the reduction of the Avrami exponent of PPS phase in PPS/TLCP blends as TLCP content increases.

\section{Phase Behavior}

The effect of the concentration of the minor component on the melting behavior of major component is usually expressed in the form of temperature-concentration phase diagram. ${ }^{16,17}$ Penning et al. ${ }^{18,19}$ constructured similar phase diagram for studying the phase behaviour of poly(vinylidene fluoride)/poly(1,4-butylene adipate) blends. In Figure 3 we present a similar temperatureconcentration phase diagram describing the overall thermal behaviour of PPS/TLCP blend system as studied by DSC. According to the phase diagram, the blend can be classified as either completely anisotropic TLCP liquid phase/isotropic PPS liquid phase (I, both component in the molten state), anisotropic TLCP Liquid phase/isotropic crystalline solid phase (II, TLCP in molten state and PPS in crystallized state), or liquid crystalline/semicrystalline solid (III, both in solid state) depending on temperature and composition. The phase diagram shows equilibrium melting transition corresponding to PPS phase, the crystal $\leftrightarrow$ nematic transition of TLCP $\left(197^{\circ} \mathrm{C}\right)$, two crystallization transitions (PPS phase crystallizes at $250^{\circ} \mathrm{C}$ and TLCP phase crystallizes at $150^{\circ} \mathrm{C}$ ), and one glass transition (at $65^{\circ} \mathrm{C}$, ascribable to TLCP phase). The $T_{\mathrm{c}}$ (corresponding to the maximum of the crystallization exotherm of PPS phase and TLCP phase) shows that both PPS and TLCP crystallizes from the mixture over a wide range of composition. It is clear that the crystal-

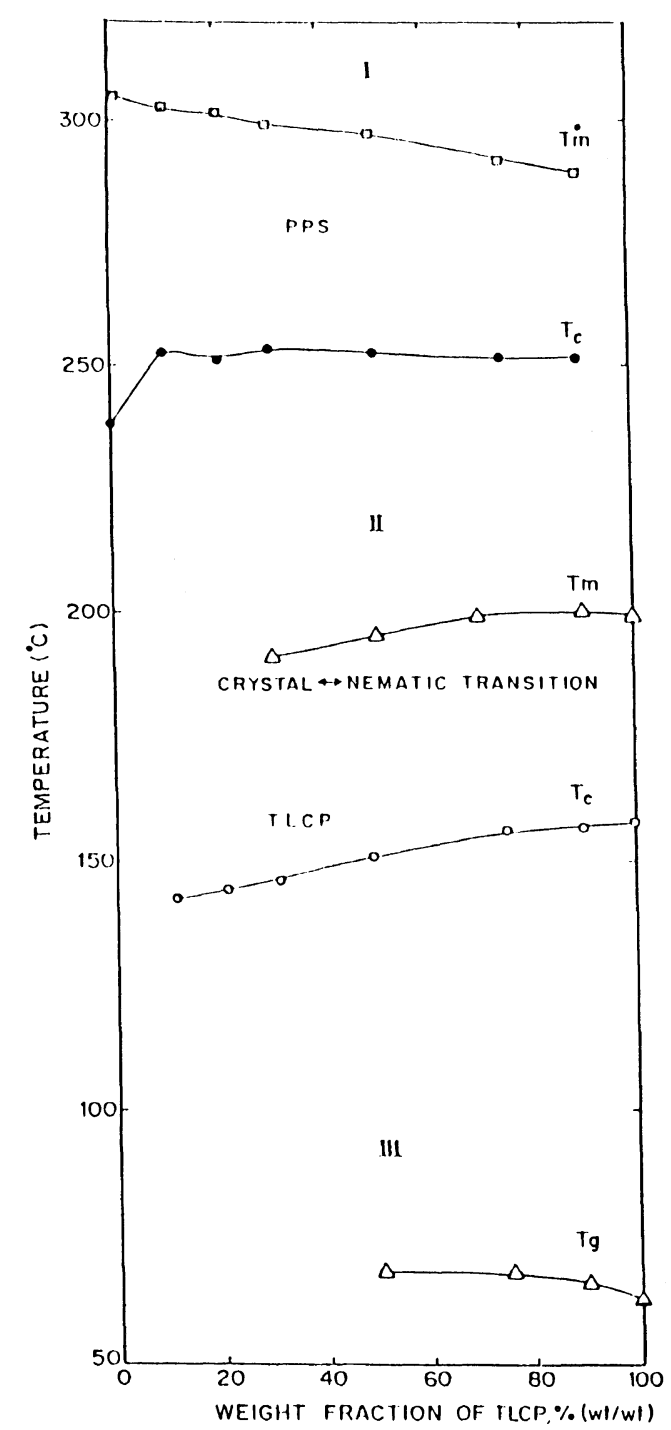

Figure 3. Phase diagram of the PPS/TLCP blend system, showing the equilibrium melting transition $\left(T_{m}^{0}\right)$ of PPS and the crystallization temperatures $\left(T_{\mathrm{c}}\right)$ of both PPS and TLCP, crystal $\leftrightarrow$ nematic transition as well as single glass transition temperature $\left(T_{\mathrm{g}}\right)$ of TLCP.

lization of PPS takes place at temperatures were above the crystal $\leftrightarrow$ nematic transition of TLCP. This means that the PPS/TLCP blends crystallizes in well separated temperature regimes and that the PPS component will always be solidified before the crystallization of TLCP starts. Therefore, the crystallization of each of the two blend components thus represents phase separation process in which the two polymers crystallize from the mixture to form separate phases. Ultimately the PPS/ TLCP blend system exists as two phases. The $T_{\mathrm{c}}^{\prime}$ (maximum of crystallization exotherm PPS phase) shifts to a higher temperature range $\left[237^{\circ} \mathrm{C}\right.$ for PPS and $251^{\circ} \mathrm{C}$ for PPS phase in $90 / 10 \%$ (wt/wt) PPS/TLCP blends].

\section{Polarized Light Optical Microscopy}

Polarized light optical microscopy offers a convenient method to follow the phase separation and crystallization mechanism of PPS/TLCP blends as a direct consequence of remarkable phase contrast between optically isotropic PPS phase and optically anisotropic TLCP phase. Three factors are known to influence the crystalline morphology 


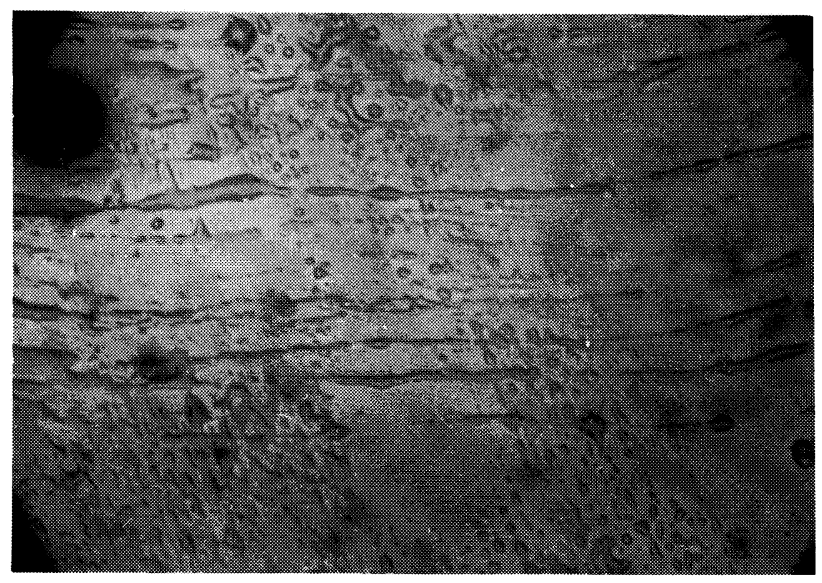

(a)

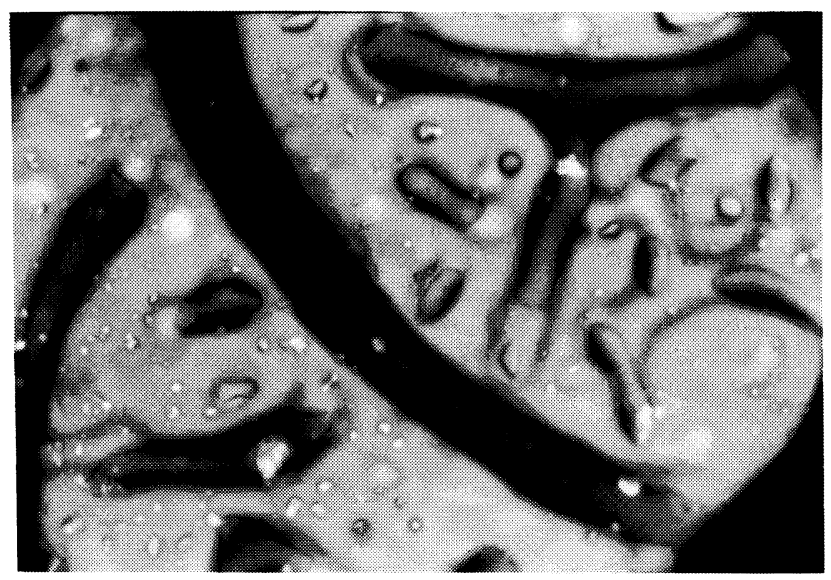

(b)

Figure 4. Optical micrographs (same magnification $=100 \times$ ) showing phase behavior of $70 / 30 \% \mathrm{wt} / \mathrm{wt}$ PPS/TLCP blend in molten state (at $320^{\circ} \mathrm{C}$ ).

of the blends. ${ }^{26}$ These are: (1) separate crystallization of blend components, (2) liquid-liquid phase separation in the melt, and (3) different crystallization rates as a function of crystallization temperature. A liquid-liquid phase separation in the melt prior to crystallization is observed for the PPS/TLCP blend system as seen from Figures $4 \mathrm{a}$ and $\mathrm{b}$. Above equilibrium melting temperature of PPS $\left(T_{\mathrm{m}}^{0}, 304.1^{\circ} \mathrm{C}\right)$, the TLCP phase exists as anisotropic oriented droplets as shown in Figure 4a. This morphology is responsible for the rheological properties, low thermal expansion coefficients and processing characteristics of the blends containing TLCP as one component. ${ }^{27}$ Due to its low crystal $\leftrightarrow$ nematic transition temperature and low melt-viscosity, TLCP phase will provide enough thermal mobility for the rapid crystallization of PPS phase. In comparison to pure PPS [Figure $5 \mathrm{a}]$, the PPS phase in $90 / 10 \%$ (wt/wt) blend exhibits spherulites smaller in size but larger in number [Figure $5 b]$. This reduction in spherulite size is in accordance with the observed depression in equilibrium melting temperature of PPS. This means that the number of nucleating sites in PPS matrix increases in the presence of TLCP as a result of heterogeneous nucleation. ${ }^{7-10}$ The crystallization temperature $\left(T_{\mathrm{c}}\right)$ and hence the rate of crystallization of PPS phase increases with the addition

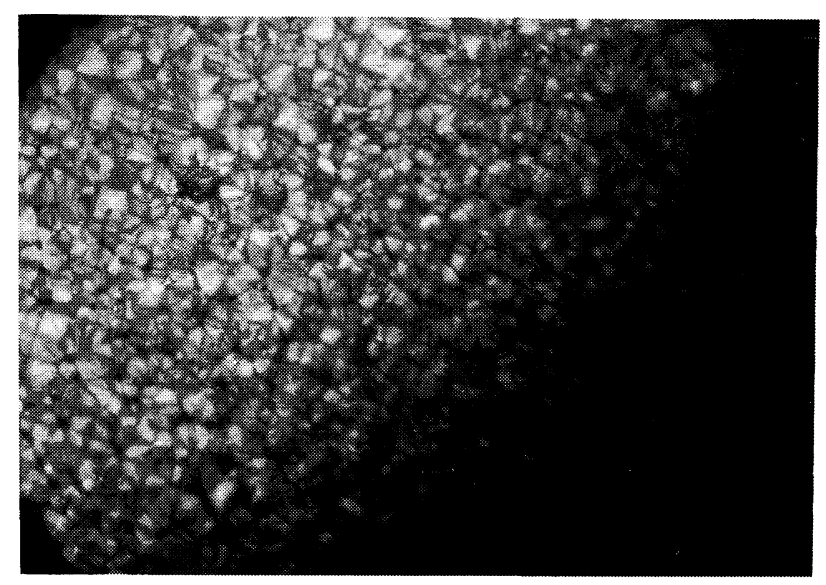

(a)

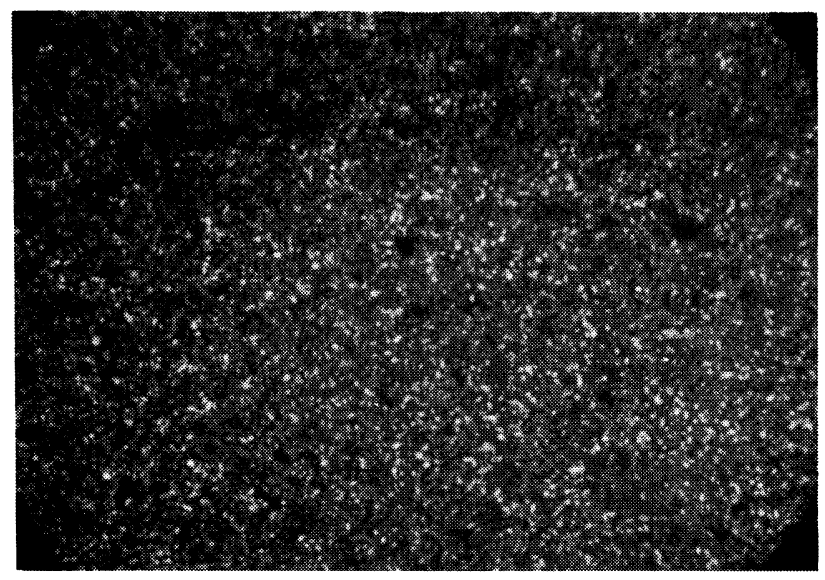

(b)

Figure 5. Optical micrographs (magnification $=100 \times$ ) showing spherulite morphology of pure PPS (a) and of PPS phase in $70 / 30 \%$ (wt/wt) PPS/TLCP blend (b).

of TLCP content as observed in phase diagram (Figure 3 ). These observations are very significant in the technological point of view because the higher crystallization rate by incorporating nucleating agents improves the productivity by shortening the molding cycle and enhances the properties of the moulded parts by developing finer grain structure. ${ }^{28}$ Work on the correlation between the structure and properties of PPS/ TLCP blends are in progress.

\section{CONCLUSION}

Blends of PPS and an aliphatic-aromatic TLCP were prepared by melt blending method. Melting, crystallization, and phase behavior of blends were investigated using differential scanning calorimetry and polarized light optical microscopy. The equilibrium melting temperature $\left(T_{\mathrm{m}}^{0}\right)$ of PPS phase and the crystal lamellar thickness decreases with increase in TLCP concentration. Phase diagram showed that the PPS phase crystallizes at a temperature well above the crystal-nematic transition of TLCP. The crystallization temperature $\left(T_{\max }\right)$ of PPS phase increases with the addition of TLCP, PLOM observation revealed that the PPS spherulite size reduces in the presence of TLCP. From these results, the fol- 
lowing conclusions can be drawn: i) the blend exists as immiscible and phase separated; ii) the TLCP phase can act as nucleating agent for the PPS crystallization; iii) the TLCP phase influences the spherulitic growth rate as well as the overall crystallization rate of PPS.

Acknowledgments. The authors would like to acknowledge Dr. Ashish Lele, and Dr. J. P. Jog for their help in conducting some part of experimental work, Dr. C. Ramesh for probing discussions. The financial support provided by Indo-French Centre for the Promotion of Advanced Research, New Delhi (Project Code: 1108-3) is also gratefully acknowledged.

\section{REFERENCES}

1. G. O. Shonaike, H. Hamada, S. Yamaguchi, M. Nakamichi, and Z. Maekawa, J. Appl. Polym. Sci., 54, 881 (1994).

2. D. G. Baird, T. Sun, D. S. Done, and R. Ramanathan, Polym. Prepr., Am. Chem. Soc., Div. Polym. Chem., 30, 546 (1989).

3. P. R. Subramaniam and A. I. Isayev, Polymer, 32, 1961 (1991).

4. P. L. Maganini, S. De Petris, M. Paci, M. Pracella, L. Minkova, A. Valenza, and F. P. La Mantia, Proceedings of Eighth Annual Meeting, Polymer Processing Society, New Delhi, 1992, p. 356.

5. M. T. Heino and J. V. Seppala, J. Appl. Polym. Sci., 44, 1051 (1992).

6. M. T. Heino and J. V. Seppala, J. Appl. Polym. Sci., 44. 2185 (1992).

7. S. M. Hong, B. C. Kim, K. U. Kim, and I. J. Chung, Polym. J., 24, 727 (1992).

8. L. I. Minkova, M. Paci, M. Pracella, and P. Magagnini, Polym. Eng. Sci., 32. 57 (1992).
9. L. I. Minkova and P. L. Magagnini, Polymer, 36, 2059 (1995).

10. B. C. Kim, S. M. Hong, S. S. Hwang, and K. U. Kim, Polym. Eng. Sci., 36, 574 (1996).

11. G. O. Shonaike, S. Yamaguchi, M. Ohta, H. Hamada, Z. Maekawa, M. Nakamichi, and W. Kosaka, Eur. Polym. J., 30, 413 (1994).

12. G. O. Shonaike, S. Yamaguchi, M. Ohta, H. Hamada, Z. Maekawa, M. Nakamichi, W. Kosaka, and K. Toi, Polym. Eng. Sci., 35, 240 (1995).

13. J. Mathew, R. V. Bahulekar, R. S. Ghadage, C. R. Rajan, S. Ponrathnam, and S. D. Prasad, Macromolecules, 27, 4021 (1994).

14. M. Eder and A. Wlochowicz, Polymer, 24, 1593 (1983).

15. J. D. Hoffman and J. J. Weeks, J. Res. Natl. Bur. Stand. A, 66, 13 (1962).

16. B. Wunderlich, "Macromolecular Physics: Crystal Melting," Vol. 3, Academic Press, New York, N.Y. 1973, Chapter 8.

17. T. Nishi and T. T. Wang, Macromolecules, 8, 909 (1975).

18. J. P. Penning and R. S. Manley, Macromolecules, 29, 77 (1996).

19. J. P. Penning and R. S. Manley, Macromolecules, 29, 84 (1996).

20. A. J. Lovinger, D. D. Davis, and F. J. Padden, Jr., Polymer, 26, 1595 (1985).

21. N. A. Mehl and L. Rebenfeld, Polym. Eng. Sci., 32, 1451 (1992).

22. G. Gabellini and R. E. S. Bretas, J. Appl. Polym. Sci., 61, 1803 (1996).

23. L. C. Lopez and G. L. Wilkes, Polymer, 29, 106 (1988).

24. P. J. Flory, "Principles of Polymer chemistry," Cornell University Press, Ithaca, N.Y., 1953.

25. T. G. Gopakumar, R. S. Ghadage, C. R. Rajan, S. Ponrathnam, and A. Fradet, Polymer, 38, 2209 (1997).

26. R. Thomann, J. Kressler, S. Setz, Ch. Wang, and R. Mulhaupt, Polymer, 37, 2631 (1996).

27. T. G. Gopakumar, R. S. Ghadage, C. R. Rajan, S. Ponrathnam, and $\mathrm{A}$. Fradet, to be communicated.

28. V. M. Nadkarni and J. P. Jog, J. Appl. Polym. Sci., 32, 5817 (1986). 